\title{
Beach-dune modelling in support of Building with Nature for an integrated spatial design of urbanized sandy shores
}

Kathelijne Wijnberg ${ }^{1}$, Daan Poppema ${ }^{1}$, Jan Mulder ${ }^{1}$, Janneke van Bergen', Geert Campmans', Filipe Galiforni-Silva', Suzanne Hulscher'1, \&

\section{Paran Pourteimouri ${ }^{1}$}

1. University of Twente, Water Engineering and Management

2. Delft University of Technology, Faculty of Architecture and the Built Environment 


\section{Abstract}

The long-term physical existence of sandy shores critically depends on a balanced sediment budget. From the principles of Building with Nature it follows that a sustainable protection of sandy shores should employ some form of shore nourishment. In the spatial design process of urbanized sandy shores, where multiple functions must be integrated, the knowledge and the prediction of sediment dynamics and beach-dune morphology thus play an essential role. This expertise typically resides with coastal scientists who have condensed their knowledge in various types of morphological models that serve different purposes and rely on different assumptions, thus have their specific strengths and limitations. This paper identifies morphological information needs for the integrated spatial design of urbanized sandy shores using BwN principles, outlines capabilities of different types of morphological models to support this and identifies current gaps between the two. A clear mismatch arises from the absence of buildings and accompanying human activities in current numerical models simulating morphological developments in beach-dune environments.

\section{KEYWORDS}

beach-dune modelling, urbanized shore, coastal spatial design, building with nature, wind-driven sediment dynamics 


\section{Introduction}

Coastal dunes on sandy shores provide multiple ecosystem services to urbanized coastal areas: they protect against flooding by offering a buffer against storms and a higher ground to live on (a regulating ecosystem service), provide drinking water by collecting and filtering water in the coastal freshwater lens (production service) and provide an attractive environment for leisure and beach tourism (cultural service). A good spatial design for an urbanized beach-dune area takes the full spectrum of these functions into account. However, these desired ecosystem services can only exist by the grace of the supporting ecosystem services. Therefore, a truly integrated spatial design not only combines all desired functions into a favourable spatial arrangement, it must also explicitly take into account and use the supporting ecosystem services.

In the case of dynamic landscapes like sandy shores, the prime supporting ecosystem service is the sediment cycle. The long-term physical existence of sandy shores depends critically on a balanced sediment budget, which is closely connected to sea level rise. Therefore, sediment budgets and -dynamics are essential in any sustainable spatial design of urbanized sandy shores. This leads to our definition of Building with Nature (BwN) for sandy shores: using natural forces (waves, tides, wind) and morphodynamics to redistribute sediment to desired locations in order to achieve integrated spatial design goals.

Solutions for coastal protection are needed most where shores are urbanized. Developing such solutions in urbanized coastal landscapes following BwN principles requires an integrated spatial design, which not only introduces additional, and possibly contrasting, functional demands, but also adds the new challenge of how different functions will interact morphologically. On many urbanized shores, the built environment encroaches onto the beach in the form of beach restaurants or series of beach huts in front of the dune, and related infrastructure such as board walks and concrete pathways (figure.1). Such structures interact with wind-driven flows of sediment that are an inherent part of BwN solutions to protect the shore. Therefore, making an integrated spatial design to solve these conflicts - or more likely prioritize and optimize accordingly - requires knowledge of both functional demands of the services and of morphological interactions between them.

The essential role of sediment dynamics in BwN design makes morphologic modelling a crucial part of the design process. The challenge for spatial designers is to develop spatial designs in a beach-dune environment that must remain dynamic because of its BwN functionality. 


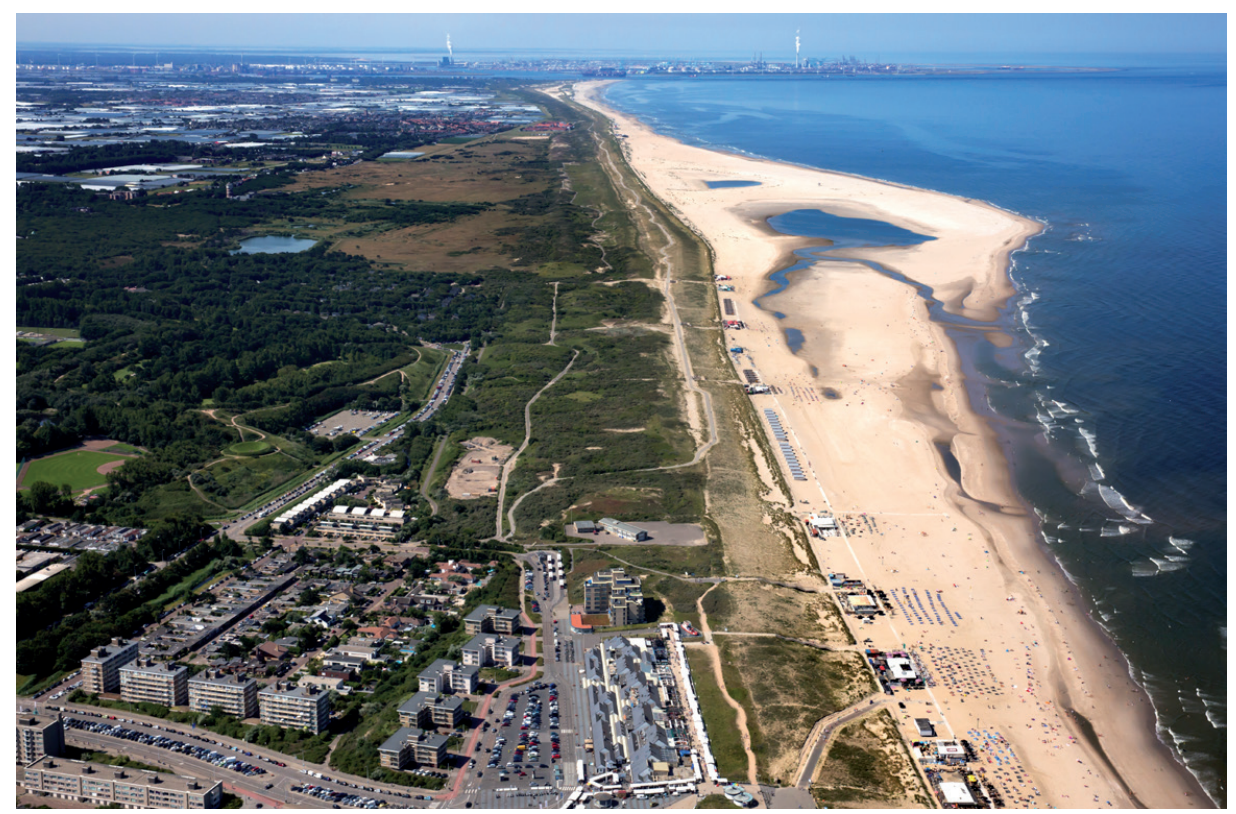

Figure 1. Example of urbanized shore with 'Building with Nature' intervention; Kijkduin, Sand Motor mega-nourishment, The Netherlands. (Source: Zandmotor, 2017)

This implies they not only need to understand how static structures interact with the wind-driven sediment flow but, as part of the spatial design process, also need to actively use such interactions. This way a true BwN design solution is achieved where presence and location of structures become part of a dynamic spatial design for urbanized shores. To do so, morphological models are needed to evaluate the impact of different possible spatial designs and design principles. (See Van Bergen et al., 2020, for actual examples of such design principles).

Numerous coastal morphological models have been developed by coastal scientists and coastal engineers for various purposes. However, it is often unclear for spatial designers what can be expected from these models with respect to level of detail of the simulation, accuracy, temporal and spatial scales of problems for which models are suitable. Furthermore, models describe certain aspects more accurately than others because modelers develop their models with a certain purpose in mind.

To our knowledge, modelers so far have never specifically considered the information needs of spatial designers when developing beach-dune models. Therefore, this paper identifies morphological information requirements in the spatial design process of urbanized sandy shores using BwN principles. It also outlines the capabilities and limitations of different types of morphological models to simulate impacts of constructions on beach-dune development. To bridge the 'language gap' between spatial designers and mor- 
phological modelers, we have attempted to avoid jargon, or explain it, and illustrate different approaches through examples from the ShoreScape ${ }^{1}$ pro- $^{-}$ ject. Hereby, we aim to match the morphological information requirements of spatial designers and morphological model capabilities to identify knowledge gaps where current models do not match information needs for integrated spatial design of urbanized shores.

\section{Morphological information needs for integrated spatial design of urbanized shores}

An integrated spatial design of urbanized sandy shores requires understanding and prediction of sediment dynamics and morphological change in interaction with a (possibly) dynamic built environment (Van Bergen et al, 2020). The specific morphological information needs vary during the different phases of the design process, as outlined below.

In the 'inquiry and analysis' phase of the design process, design requirements and context are explored to grasp the parameters of the urban and eco-morphological spatial systems involved. In the case of a $\mathrm{BwN}$ approach, this requires information on the dynamic context. That is not just spatial characteristics of the system at a given time, as can be represented in a Geographical Information System (GIS), but of the full system's behaviour. For instance, considering a specific nourishment scheme, which beach width variation over time, or which combinations of dune height and width can be expected to develop in areas of a planned waterfront design? What are characteristic bed level profiles across the beach-dune zone during this development? Which morphodynamic mechanisms exist to direct the location and amount of erosion and deposition using buildings placed at the beach (such as already present on Fig. 1 for recreational use)? Additionally, in this phase of the design process rules of thumb are desired that summarize interactions of buildings with wind-driven sediment flows. For instance, a simple formula describing the relation between inter-building spacing and the amount of blockage of wind-driven sediment flow. Similarly, what would be the sediment blockage factor of raised buildings as a function of their vertical distance above the beach?

The above type of information is important for understanding landscape and urban processes and to identify parameters for the exploration of possible futures. Integrated spatial designs for urbanized shores with wide beaches, rapidly eroding shorelines and large spatial variations therein, such as at

1 ShoreScape is a research project that aims to develop knowledge, tools and design principles for the sustainable co-evolution of the natural and built environment along sandy shores. 
the Sand Motor (figure 1), will most likely differ from those with more gradual advancing shoreline positions and slowly seaward advancing dune fronts.

In the subsequent phase of 'design feasibility', different spatial arrangements are tested and combined into one design. Interactions of urban design and morphological development are studied by so called 'rapid prototyping'. For example, when planning for beach housing in a dune formation zone, various layouts are explored by systematically varying the types and configurations of buildings and the timing of their placement. A combination of several design aspects will lead to variants and plausible solutions, ready to fit the dynamic context and urban program.

Finally, in the phase of 'design optimization', interactions between different design aspects are studied in detail and optimized. Now decisions have to be made that have financial consequences and thus require a higher level of accuracy and precision of morphological information. For example, when considering sea level rise, a proposed nourishment scheme and arrangement of beach houses should guarantee natural growth of the dunes, such that flood safety levels and natural values provided by the dunes will be maintained. This requires detailed information about, amongst others, the amount of sand in the dunes over time, including a prediction of its topographic evolution, to enable the application of models that test flood safety levels through time. This optimization process will lead to a favourable solution, underpinned by quantitative tests based on the output of morphological modelling.

\section{Model types for evaluating morphodynamics of the beach- dune system on urbanized sandy shores}

In the context of simulating topographic changes (related to sand transport by wind and water) in a beach-dune environment, the term 'model' or 'morphodynamic model' refers to a simplified version of reality that, in its very essence, incorporates topography (bed elevation) and the sediment transport processes that change it. Models differ in how they incorporate sediment transport processes. Broadly, we can identify three types of models, differing in their simplification approach: conceptual models, physical models ((scaled) lab experiments), and numerical simulation models. For a beach dune environment, numerical simulation models can be split into process-scale models and rule-based behavioural models. In the following, we will explain these different modelling approaches, what type of information they can provide as well as their present, or inherent, limitations. 


\section{Conceptual models}

In the context of morphodynamic modelling, a conceptual model refers to a schematization of the beach dune systems in a qualitative manner. It describes, in words, how beach-dune topography changes under the influence of one or more factors (such as wind, waves, or sediment surplus), often with the help of diagrams and sketches. Relations between factors and bed level changes are often described in terms of positive or negative feedback. Conceptual models can be based on a combination of phenomenological knowledge, derived from field observations, and theory (first principle physics, analogies). For example, Psuty (2004) describes how various dune typologies develop on accreting and eroding beaches and links these with a diagram of sediment budget curves for beach and foredune (figure.2).

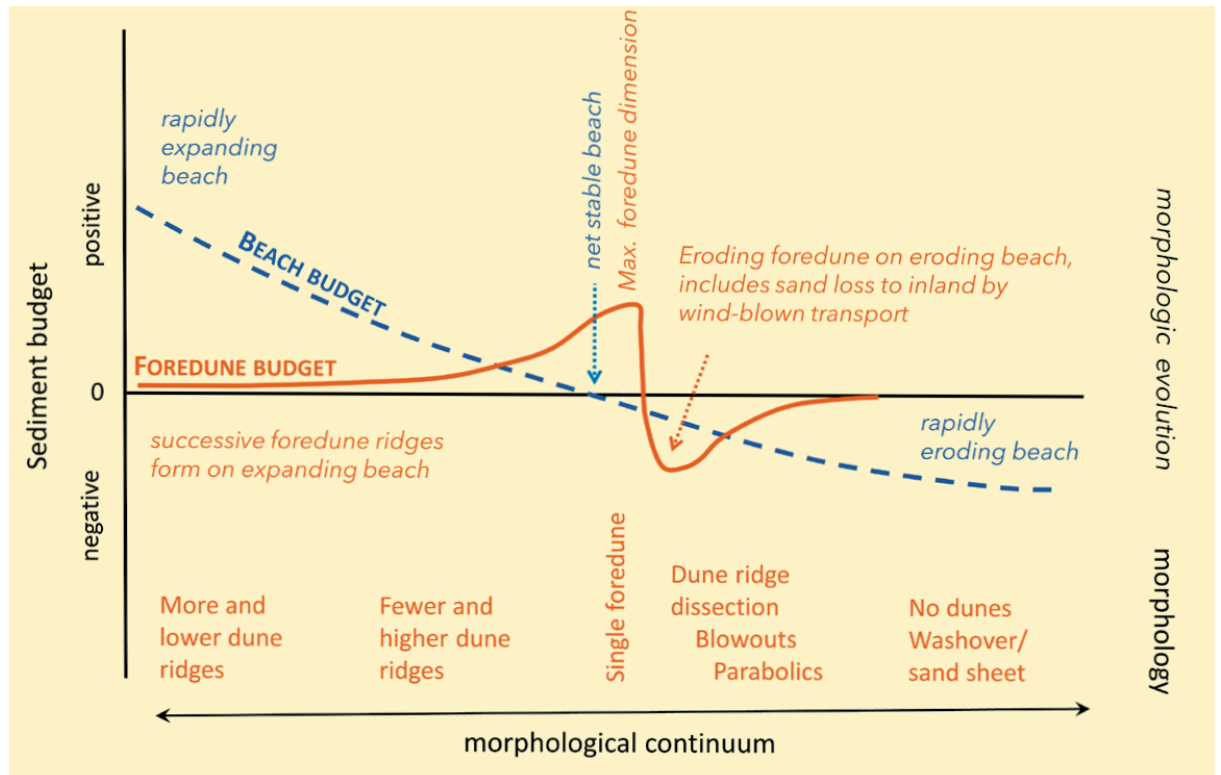

Figure 2. Example of a conceptual model, showing the relationship between the sediment budget of the beach and the resulting sediment budget of the foredune with related topographies of this sand-sharing system. Note that for the situation of a slightly negative sediment budget of the beach, maximum sand storage in the foredune (max. foredune dimension) and maximum inland sand transport expressed through parabolic dune development, are closely positioned and may even occur simultaneously along a given coastline (modified after Psuty, 2004).

Rules of thumb also are conceptual models and have a quantitative element to them. For example, in a given region, initiation of sand-drift dikes ${ }^{2}$

2 A sand-drift dike (stuifdijk) is an artificially created linear dune ridge, initiated by erecting long lines of reed bundles and willow on coastal sandflats to capture windblown sand, often accompanied by planting marram grass at a later stage. Traditional Dutch coastal maintenance practice (see Boeschoten, 1954). 
will be unsuccessful when the sandflat is less than $1.3 \mathrm{~m}$ above mean sea level (Boeschoten, 1954). Rules of thumb are often based on empirical relations that may be derived from field monitoring or lab experiments (physical models), although they may as well form a way of schematizing insights derived from numerical simulation models. Empirically derived, as well as process-scale modelling-derived rules of thumb can form input for rule-based morphodynamic simulation models.

A conceptual model generally forms the basis for developing a numerical simulation model by providing the elements that may be quantified in numerical simulation models. Conceptual morphological models themselves do not provide quantitative information on rates of change, sediment volumes, or specific complications that could arise from interventions. Morphological experts may use conceptual morphological models to provide:

- a fast overview of possible, first order impacts on morphology of interventions/designs or objects

- rules of thumb for indicating types of natural topographic evolution to be expected in different zones of the beach dune system.

\section{Physical models - scaled lab experiments}

A physical model is a tangible representation of a natural system, simplified, but still faithfully reflecting important relationships between relevant processes. Observations and measurements in a physical model can be used to infer information about the behaviour of the natural system itself. As physical models are often built on a reduced spatial and temporal scale, they are also called scale models.

In coastal studies, physical models are mostly used to examine hydrodynamics and morphodynamics and are generally developed in a laboratory setting. For instance, Boers et al. (2009) used a wave basin to study storm erosion of a scaled dike-and-dune system; wind flow around buildings or over dunes can be studied in wind tunnels (e.g. Fackrell, 1984; Wiggs et al., 1996). Occasionally, physical experiments are located in a field setting. For example, Visser et al. (1991) conducted a full-scale dike breach experiment at Het Zwin. Other examples are scale experiments at the beach examining effects of building geometry on sedimentation and erosion patterns in their surroundings (Poppema et al, 2019).

The reduced complexity and scale of physical models, in comparison to the full-scale, real world setting, makes them flexible, relatively cheap and easy to adapt, and suitable to:

- Investigate archetypical situations and underlying principles (e.g. Fackrell (1984) and Martinuzzi and Tropea (1993) on the flow structure around a 
cube);

- Systematically vary a specific variable to investigate its effects (e.g. gradually increasing wind speed to examine deposition patterns around houses like Liu et al. (2018) did for snow accumulation);

- Answer explorative design questions (e.g. 'can a funnel-shaped configuration of a series of beach huts, located seaward of the dunes, induce locally increased sediment supply towards the dunes?');

- Evaluate design performance (e.g. 'Does beach house configuration X lead to the desired sedimentation pattern?').

Physical models also have drawbacks and limitations. As for all types of models, processes not included in the model can be an issue (e.g. growing vegetation). On top of this, a basic problem of physical models is scaling. If the geometry is scaled (e.g. using a 1:20 scale model of a beach house in a wind tunnel experiment), a faithful representation of real world conditions regarding wind and sediment requires other properties (such as weights, forces, velocities, and time scale) to be scaled as well. This scaling involves physical scaling laws that may pose conflicting constraints on how scaling should occur. As a result, scaling cannot be perfect, and the model maker has to decide which processes are chosen and scaled properly.

An example application of physical models in the context of urbanized beach modelling, is to examine effects of building size and shape on size and location of deposition and erosion patterns. In the ShoreScape project, we placed cuboid scale models of buildings with various dimensions on the beach (see Fig. 3) in order to derive general rules for the effects of building dimensions that can be used in rule-based morphological computer models (see section 14.3.4). We placed the scale models on the beach instead of in a wind tunnel to reduce some of the scaling issues and remove limitations of the physical size of a wind tunnel. By using scale models, instead of full-scale objects, one can more easily vary test configurations. Other advantages of field deployment are that longer-term effects with changing wind conditions can be examined and that inherent natural wind and sand transport variations are automatically captured. This simultaneously brings a clear disadvantage of field deployment: one cannot control weather conditions, hence experiments performed on different days will experience different wind conditions, complicating a comparison of results on different days and requiring careful interpretation. The latter can be supported by developing complementary numerical modelling experiments using CFD (see Section 14.3.3) where the influence of different wind speeds can be systematically studied and understood. 

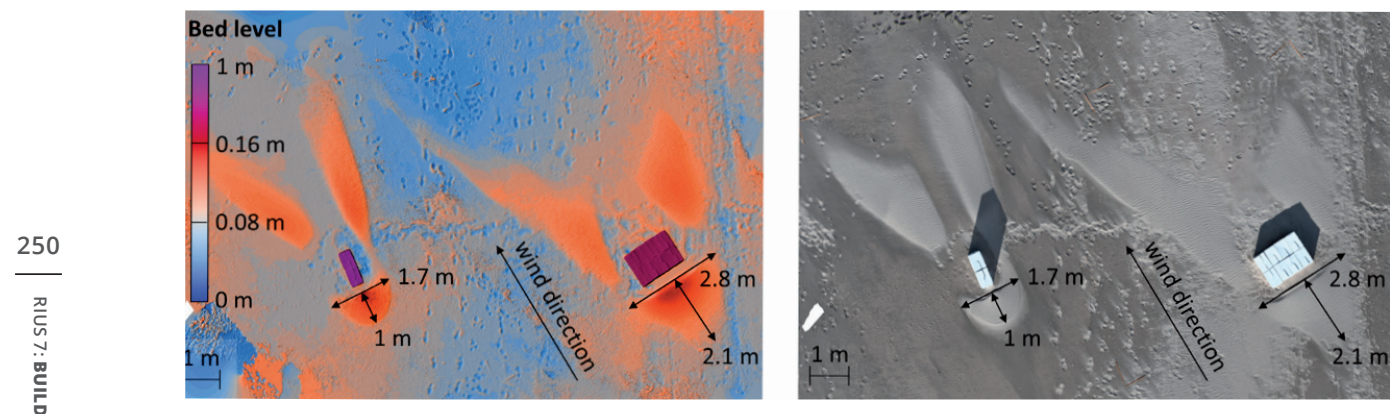

Figure 3. An elevation map (left) and orthophoto (right), showing the erosion and deposition around the same set-up with two scale models of buildings that differ in width. As an example, the measured dimensions indicate that both the width and length of the deposition upwind of the models increase with increasing scale model width.

\section{Process-scale numerical simulation models using CFD}

Computational Fluid Dynamics (CFD) is a method enabling computers to solve problems of flow in liquids as well as gasses. In fluid dynamics, flow is described by fundamental physical laws, which include continuity of mass, momentum and energy. These laws describe how these quantities change in time and space due to physical processes. This means that flow properties like density, velocity, pressure and temperature are described through these equations. In practice, the model equations are not easy to solve. Numerical techniques can be used to find approximate solutions for these equations, as the continuous model equations cannot be solved directly. Therefore, the model equations are discretized into a set of algebraic equations. This can be achieved by subdividing the computational domain into a finite number of small cells. These discrete equations can then be solved to find approximate solutions of flow properties.

Sediment transport depends on flow conditions, so CFD can be used to obtain the forcing of sediment transport models. Spatial variations in the fluid flow near the sand surface result in spatially variable sediment transport rates, which causes bed level changes through erosion at one location, and deposition at another. In return, these bed level changes again affect the flow field, closing the feedback loop, also known as a morphological loop.

Using CFD to solve flow problems has advantages but also limitations. By increasing the number of cells, the numerical solution converges toward the exact solution. Therefore, this solution method can be very powerful for finding flow properties in high resolution in time and space. However, increasing the number of cells also increases the computational time required. Therefore, in CFD simulations, there is always a balance between computational cost and resolution. In comparison with field experiments, where all variables 
are constantly changing, CFD simulations allow a systematic investigation of the impact of specific variables of interest. Numerical modelling can be a powerful tool for providing insight into physical processes. Model results are often simplifications of reality and will therefore not replace experimental research, but rather be complementary to experiments.

This makes CFD models suitable to:

- Systematically vary the value of a specific variable to investigate its effects. Parameter values can be precisely specified, or certain processes can be eliminated to focus on processes of interest. (e.g. gradually increasing wind speed to examine influence on size of erosion and deposition patterns around houses)

- Focus on specific aspects of the problem of interest by turning processes on and off in simulations. Processes that could be investigated are for instance: does soil moisture affect wind driven sediment transport.

- Compute detailed flow and sediment transport estimates around a single design for very short timescales (up to minutes) and a limited number of conditions. Solving airflow equations around buildings requires solutions for a wide range of spatial scales; from the large-scale flow around the building to small-scale flow structures in the turbulent wake behind the building. Even though the small-scale flow structures will be parameterized, the wide range of spatial scales limits the simulated time to several minutes. Computational times typically take hours or days.

- Obtain system knowledge through CFD, which can result in rules of thumb.

Even though computers become increasingly powerful, solving turbulent wind flow at the required level of detail and fast enough for a long-term morphological evolution of quantitative accuracy, is not yet realistic. Average flow simulations can be used but result in a lack of physics on smaller scales. Note that most morphological models used in coastal engineering applications are hydro-morphodynamic models that use a more schematized way of CFD modelling, with cell sizes of tens to hundreds of meters and often only depth-averaged fluid flow instead of the full 3D flow field. These models can be applied to simulate the development of the submerged nearshore seabed and can be used, for instance, to evaluate the longer-term shoreline evolution of mega-nourishments due to waves and currents.

A preliminary result of the use of CFD modelling in the ShoreScape project is shown in Fig. 4. CFD can provide detailed airflow patterns around various geometries and arrangements of beach houses. Aeolian sediment transport can then be computed by using sediment transport equations that are dependent on bed shear stress and near bed flow velocities, which are calculated for each cell in the computational domain of the CFD model. The morpholog- 
ic change is derived from the conservation of sediment. Simulations can be made for full scale beach houses, but also at the scale of the physical model experiments at the beach by Poppema et al (2019) to support interpretation of observed sedimentation patterns in terms of underlying mechanisms and test for possible scaling effects.

(a)

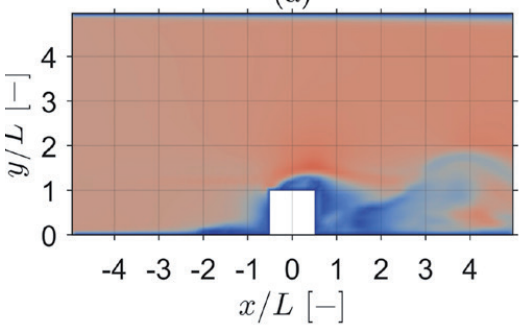

(b)

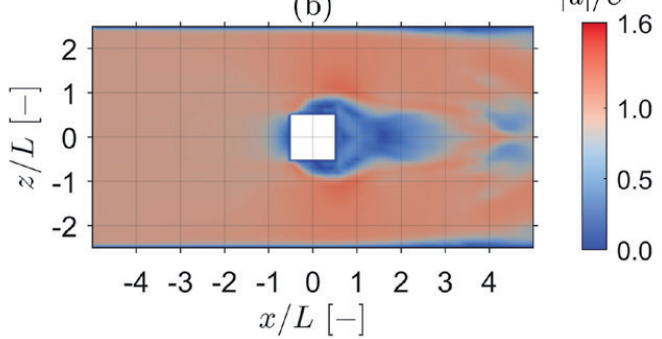

Figure 4. Example snapshot of calculated flow field around a cube-shaped building using CFD modelling: a) side view, slice along centre line $z / L=0, b$ ) top view, slice along $y / L=0.5$. Fluid flow from left to right. Blue to red colours indicate low to high flow velocities.

\section{Rule-based coastal morphodynamic models}

Like CFD models, rule-based morphodynamic models describe the beach-dune topography using a large number of cells on a regular grid, usually a two-dimensional surface. The difference lies in the rules that describe the behaviour of these cells. Discrete numbers represent the state of each grid cell (e.g. its elevation, density and type of vegetation in the cell, depth of groundwater). Cell states can change according to transition rules that define how the current state of a cell depends on the previous state of this cell and of its surrounding cells. For example, the probability of sediment deposition in a cell depends on the presence of vegetation within the cell (which would trap sediment) and on the presence of a higher elevation in an upwind cell (a dune creates a shadow zone with decelerated wind and increased deposition behind it). This type of model, with grid cells and discrete cell states governed by transition rules, is most commonly referred to as Cellular Automata (CA) model (Fonstad, 2013).

The evolution of the beach-dune topography is calculated by applying these transition rules multiple times to all grid cells, where each iteration (i.e. application of the rules to all grid cells in the model) represents a time step. The mathematical functions that control cell state transitions can be as simple, or complicated, as desired to achieve the aim of the model. To create a meaningful CA model of a natural system, a physical rationale for the mathematical functions of each transition rule is essential. Transitions should be based on general rules or on empirical estimates derived from measurements and must account for all necessary processes required for the desired pattern/ phenomena. 
So far, the DUBEVEG (Dune, Beach and VEGetation) model (Keijsers et al., 2016, Galiforni-Silva et al., 2018, 2019) is the only attempt to simulate beachdune development solely using a CA approach. It includes the main processes involved in the dynamics of the beach-dune system, such as wind-driven sediment transport, vegetation growth and decay, hydrodynamic erosion and supply, and groundwater depth. Model rules are applied with a weekly time step, under the assumption of a given long-term average wind-driven sand transport. This results in short computing times, making the model suitable for long-term morphodynamic studies over tens of years.

The main advantages of CA modelling are its flexibility and range of modelling possibilities with a relatively low computational effort. Rules can be simple and are usually easily adaptable. For instance, DUBEVEG only needs sediment transport rules without separate rules for fluid flow (air or water), contrary to CFD models where repeated fluid flow computations are an essential and computationally intensive component.

A limitation of the beach-dune CA model is that total aeolian sediment supply is user-specified, either derived from other models or from long-term monitoring data. This implies that the total wind-driven sediment volume increase, totalled over the simulated period, is imposed by the user and not an outcome of the interacting processes in the model. Also, because CA models focus on interactions at a certain location (e.g. changes in sand transport around a dune), rather than the movement of objects through space (e.g. the transport of sand grains), the model does not simulate sand fluxes as required for commonly used model validation methods (e.g. comparison to a measured sand flux). CA model outcomes can therefore only be validated at a higher level of aggregation, such as overall trends and spatial patterns in morphology. Hence model outcomes cannot be used as a quantitatively accurate prediction or reproduction of beach-dune topography at a given time.

Following from all advantages and limitations, CA models for beachdune dynamics are currently useful as exploratory rather than predictive tools. Their characteristics make them suitable for:

- Investigating underlying principles of archetypical situations (e.g. can dune formation be explained solely from shadow zone effects and avalanching when slopes become too steep?).

- Investigating process interactions ('How do seasonally present houses in front of a dune affect this dune?')

- 'Rapid prototyping' to answer explorative design questions (e.g. 'can strategic, time-varying placement of beach houses help build up a dune?')

- Qualitatively comparing designs ('will a design with larger distances between houses result in a higher dune? ') 
An example of the output of a CA model simulating the impact of beach houses on dune development is shown in Fig. 5. Here, a series of beach houses are implemented in the CA model DUBEVEG by defining non-erodible cells and adding a rule that states a zero probability for sand deposition on top of a house. The nine houses are $2.5 \mathrm{~m}$ high, $4 \mathrm{~m}$ wide, and $10 \mathrm{~m}$ long, and have a 4 $\mathrm{m}$ spacing. As we used the DUBEVEG version described in Galiforni-Silva et al (2018), specific rules for the impact of rectangular objects on sedimentation/erosion patterns have not yet been implemented.
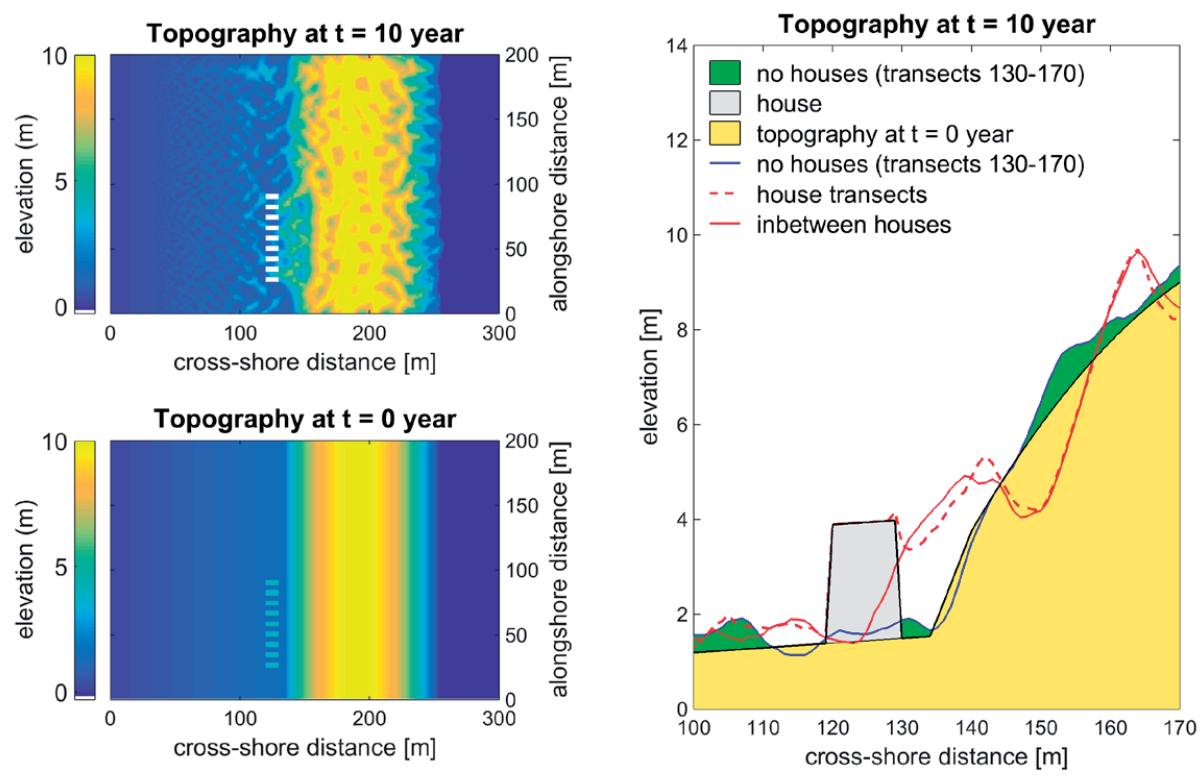

Figure 5. Example illustrating a possible outcome of implementing beach houses in a CA model, where it should be noted that the CA model used does not yet include rules that specify the impact of bluffbody objects, such as beach houses, on local sedimentation-erosion patterns. a) Top view of beach-dune topography after 10 years simulation, white rectangles represent beach houses; b) top view of beachdune topography at start of simulation, rectangles represent beach houses; c) average topography along transects crossing the middle of a beach house (red dashed), transects in between beach houses (red solid), transects without beach houses (black solid, where green infill indicates sedimentation).

\section{Matching morphological information needs and}

\section{morphological model capabilities}

A BwN approach for developing integrated spatial designs for urbanized sandy shores requires morphological modelling at both small and large scales. It requires models to predict the larger scale evolution of the coastline under different nourishment strategies as well as the evolving topography of beach and dunes on smaller scales. For the latter, understanding shorter term 
interactions of wind-driven sediment transport, vegetation growth, dune development, human use and the built environment are essential to simulate the long-term consequences for the upper beach and dune evolution. Understanding and modelling these complex interactions, where sediment has to move from the submerged domain to the subaerial domain and interact there with the biotic system and the socio-economic system is at the frontiers of coastal modelling (Lazarus et al, 2016).

In the 'inquiry and analysis' phase of spatial design, conceptual models, physical scale models, and CFD models all contribute to meeting identified morphological information needs. In this context, CFD modelling serves two main purposes. Firstly, detailed 3D airflow simulations combined with sediment transport calculations may enhance insight into underlying mechanisms of building impacts on erosion/sedimentation patterns, leading to rules of thumb. Secondly, coarse grid CFD models (grid size of tens to hundreds of meters) with highly reduced complexity fluid flow equations or surrogate modelling techniques (e.g. Berends et al., 2019), can be used to provide morphological information on the approximate effects of nourishment schemes on the coastal profile or shoreline position over many years to a few decades. Regarding modelling of wind-driven sedimentation and erosion around buildings, many studies exist that model airflow around buildings (e.g. Ozmen et al., 2016), but none have calculated related sediment transport patterns. A few modelling studies exist where zones of acceleration and deceleration of the wind near the sand surface, induced by the building, were interpreted as zones of erosion and deposition (e.g. Van Onselen, 2018). Note that the process-scale numerical modelling of wave- and current-driven sedimentation and erosion around hard coastal protection structures at urbanized shores, such as seawalls, is much more advanced (e.g. Smallegan et al., 2016; Muller et al, 2018)

In the phase of 'design feasibility', it is 'rapid prototyping' that puts high demands on the computational time of long-term morphological simulations (covering several years to tens of years). It requires numerical models that can quickly evaluate morphological effects of multiple spatial design alternatives, considering the interaction of buildings and sediment flows, as well as interaction with vegetation development (all of which influence dune formation). This makes CA models currently the most suitable type of model, even though they do not yet include rules for interactions of buildings with wind-driven sand transport. Also, it has been observed that activities related to the recreational use of the beach, such as beach raking or beach traffic, may affect vegetation growth and hence dune development, as does local mechanical removal of aeolian sand deposits by property owners (Jackson and Nordstrom, 2011). Respective relations are still lacking in current beach-dune morphological models. 
Regarding the phase of 'design optimization', expressed morphological information requirements seem to be rooted in the tradition of static spatial designs, where the final design can be highly detailed and precise. However, in the case of BwN-based spatial designs, the final design is not a static situation but an inherently dynamic, evolving situation and a static end situation will never exist. Regarding the assessment of flood defence functionality of future dune landscapes, adaptive approaches may be needed (cf. Vuik et al, 2018). Moreover, the assessment of the safety level of a dune with hard objects in or on top of it, is still a difficult issue (e.g. Boers et al., 2009). Apart from the difficulties of knowing details of future beach-dune topography, even predicting the total amount of sand in a dune area is still a major challenge. No models are available yet for accurate prediction of long-term sediment supply to the dunes. Recent efforts in coupling subaqueous and subaerial domains in numerical model studies (e.g. Roelvink and Costas, 2019; Hallin, 2019) help to obtain quantitative insight in the time-varying amount of sand supply that is delivered by the waves and tides and can be picked up by wind for continued onshore transport. In short, present-day capabilities of morphological models to support design optimization are still limited.

\section{Conclusion}

Using 'Building with Nature' principles in the spatial design of urbanized sandy shores asks for a new design approach. A recognition of the interconnectedness between urban and morphological spatial systems implies the need for dynamic and adaptive, instead of static, designs. Combining the demand for multi-functionality - flood protection, nature, recreation and economy - while at the same time explicitly considering and utilizing sediment dynamics, requires truly integrated spatial design. This poses new challenges to morphological models supporting it.

Numerical models (computer models) able to accurately predict the morphological effects of interaction between wind-driven sediment dynamics and buildings are currently lacking. This is most severely felt in the phases of 'design feasibility' and 'design optimization', where alternatives like conceptual and physical models - particularly useful in the 'inquiry and analysis' phase - are less suitable. In the 'design optimization' phase, a gap exists between model capabilities and morphological information needs as it is difficult to accurately predict the long-term sediment supply to dunes with numerical models. Finally, the observed influence of human activities on urban beaches on vegetation development is currently absent in all morphological models. Hence predicted location and/or rate of new dune formation will be inaccurate for urbanized beaches. 
To conclude, arriving at integrated spatial designs for the sustainable protection of urbanized sandy shores using BwN principles requires morphological models that can go beyond the hydro-morphological simulation of nourishment behaviour alone and can include interactions with how humans use the beach.

\section{Acknowledgements}

This paper has been written in the framework of the ShoreScape project (Sustainable co-evolution of the natural and built environment along sandy shores), funded by the Netherlands Organization for Scientific Research (NWO), contract number ALWTW.2016.036, co-funded by Hoogheemraadschap Hollands Noorderkwartier and Rijkswaterstaat, and in kind supported by Deltares, Witteveen\&Bos, and $\mathrm{H}+\mathrm{N}+\mathrm{S}$ Landscape Architects. 
Berends, K. D., Scheel, F., Warmink, J. J., de Boer, W. P., Ranasinghe, R., \& Hulscher, S. J. M. H. (2019). Towards efficient uncertainty quantification with high-resolution morphodynamic models: A multifidelity approach applied to channel sedimentation. Coastal Engineering, 152, 103520. https://doi. org/10.1016/j.coastaleng.2019.103520

Boers, M., Van Geer, P., \& Van Gent, M. (2011). Dike and dune revetment impact on dune erosion. In: M. Mizuguchi \& S.Sato (Eds.), The Proceedings of Coastal Sediments 2011, 810-823. doi: 10.1142/9789814355537_0061

Boeschoten, J. C. (1961, January). Stuifdijken op Terschelling en Vlieland (No. 330267). Ministerie van Verkeer en Waterstaat, Rijkswaterstaat, Directie Friesland (RWS, FR). https://puc.overheid.nl/rijkswaterstaat/doc/PUC_122849_31/1/

Fackrell, J. E. (1984). Parameters characterising dispersion in the near wake of buildings. Journal of Wind Engineering and Industrial Aerodynamics, 16(1), 97-118. https://doi.org/10.1016/0167-6105(84)90051-5

Fonstad, M. A. (2013). 2.9 Cellular Automata in Geomorphology. In J. F. Shroder (Ed.), Treatise on Geomorphology (pp. 117-134). Academic Press. https://doi.org/10.1016/B978-0-12-374739-6.00035-X

Galiforni Silva, F., Wijnberg, K. M., de Groot, A. V., \& Hulscher, S. J. M. H. (2019). The effects of beach width variability on coastal dune development at decadal scales. Geomorphology, 329, 58-69. https://doi. org/10.1016/j.geomorph.2018.12.012

Galiforni-Silva, F., Wijnberg, K. M., de Groot, A. V., \& Hulscher, S. J. M. H. (2018). The influence of groundwater depth on coastal dune development at sand flats close to inlets. Ocean Dynamics, 68(7), 885-897. https://doi.org/10.1007/s10236-018-1162-8

Hallin, C. (2019). Long-term beach and dune evolution: Development and application of the CS-model (Doctoral dissertation, Lund University). https://lup.lub.lu.se/search/publication/e850cf42-d671-4790-ab627c43830e7f6a

Jackson, N. L., \& Nordstrom, K. F. (2011). Aeolian sediment transport and landforms in managed coastal systems: A review. Aeolian Research, 3(2), 181-196. https://doi.org/10.1016/j.aeolia.2011.03.011

Keijsers, J. G. S., De Groot, A. V., \& Riksen, M. J. P. M. (2016). Modeling the biogeomorphic evolution of coastal dunes in response to climate change. Journal of Geophysical Research: Earth Surface, 121(6), 1161-1181. https://doi.org/10.1002/2015jf003815

Lazarus, E. D., Ellis, M. A., Brad Murray, A., \& Hall, D. M. (2016). An evolving research agenda for humancoastal systems. Geomorphology, 256, 81-90. https://doi.org/10.1016/j.geomorph.2015.07.043

Liu, M., Zhang, Q., Fan, F., \& Shen, S. (2018). Experiments on natural snow distribution around simplified building models based on open air snow-wind combined experimental facility. Journal of Wind Engineering and Industrial Aerodynamics, 173, 1-13. https://doi.org/10.1016/j.jweia.2017.12.010

Martinuzzi, R., \& Tropea, C. (1993). The Flow Around Surface-Mounted, Prismatic Obstacles Placed in a Fully Developed Channel Flow (Data Bank Contribution). Journal of Fluids Engineering, 115(1), 85-92. https://doi.org/10.1115/1.2910118 
Muller, J., Figlus, J., \& de Vries, S. (2018). Xbeach Simulation of Hybrid Coastal Protection: A Galveston Seawall Test Case. Coastal Engineering Proceedings, 1(36), papers.100. https://doi.org/10.9753/icce.v36. papers. 100

Ozmen, Y., Baydar, E., \& van Beeck, J. P. A. J. (2016). Wind flow over the low-rise building models with gabled roofs having different pitch angles. Building and Environment, 95, 63-74. https://doi.org/10.1016/j. buildenv.2015.09.014

Poppema, D. W., Wijnberg, K. M., Mulder, J. P., \& Hulscher, S. J. (2019, May). Scale experiments on aeolian deposition and erosion patterns created by buildings on the beach. In P. Wang, J. D. Rosati, \& M. Vallee (Eds.), Coastal Sediments 2019: Proceedings of the 9th International Conference (pp. 1693-1707). World Scientific. https://doi.org/10.1142/9789811204487_0146

Psuty, N. P. (2008). The Coastal Foredune: A Morphological Basis for Regional Coastal Dune Development. In M. L. Martínez \& N. P. Psuty (Eds.), Coastal Dunes. Ecological Studies (Vol. 171, pp. 11-27). Springer. https://doi.org/10.1007/978-3-540-74002-5_2

Roelvink, D., \& Costas, S. (2019). Coupling nearshore and aeolian processes: XBeach and duna process-based models. Environmental Modelling \& Software, 115, 98-112. https://doi.org/10.1016/j.envsoft.2019.02.010

Smallegan, S. M., Irish, J. L., Van Dongeren, A. R., \& Den Bieman, J. P. (2016). Morphological response of a sandy barrier island with a buried seawall during Hurricane Sandy. Coastal Engineering, 110, 102-110. https://doi.org/10.1016/j.coastaleng.2016.01.005

Van Bergen, J., Mulder, J., Poppema, D, Nijhuis, S., Wijnberg, K. \& Kuschnerus, M. (2021). Urban dunes: towards design principles for dune formation at urbanized shores. Research in Urbanism Series, 7, 101128. https://doi.org/10.47982/rius.7.130

Van Onselen, E. P. (2018). Analysing measures to improve beach-dune interaction in the presence of manmade structures using computational fluid dynamics (CFD). Report Internship at Hoogheemraadschap Hollands Noorderkwartier. University of Utrecht.

Visser, P. J., Vrijling, J. K., \& Verhagen, H. J. (1991). A field experiment on breach growth in sand-dikes. In B.L. Edge (Ed.), Coastal Engineering 1990 (pp. 2087-2100).

Vuik, V., van Vuren, S., Borsje, B. W., van Wesenbeeck, B. K., \& Jonkman, S. N. (2018). Assessing safety of nature-based flood defenses: Dealing with extremes and uncertainties. Coastal Engineering, 139, 47-64. https://doi.org/10.1016/j.coastaleng.2018.05.002

Wiggs, G. F. S., Livingstone, I., \& Warren, A. (1996). The role of streamline curvature in sand dune dynamics: evidence from field and wind tunnel measurements. Geomorphology, 17(1-3), 29-46. https://doi. org/10.1016/0169-555x(95)00093-k

Zandmotor. (2017, July 9). Juli 2017 Zandmotor vanuit noord [Photograph]. Flickr. https://www.flickr.com/ photos/zandmotor/35632520843/ 
